\title{
AC 2007-2645: RECITATION IN CORE ENGINEERING MECHANICS COURSES: IMPLICATIONS FOR RETENTION AND STUDENT PERFORMANCE
}

\section{Messiha Saad, North Carolina A\&T State University}

Messiha Saad is an Assistant Professor of Mechanical Engineering at North Carolina A\&T State University. He received his Ph.D. from North Carolina State University. He taught mechanical engineering core courses for more than twelve years; he also teaches internal combustion engines, design of thermal systems, and related courses in the thermal science areas. He is a member of ASEE, SAE, and ASME.

\section{Taher Abu-Lebdeh, North Carolina A\&T State University}

Dr. Abu-Lebdeh obtained his doctorate degree in Structural engineering from Louisiana State University. He taught civil and core engineering courses for about twenty years. Dr. Abu-Lebdeh research interests are in civil engineering and highway infrastructures, structural mechanics, and constitutive modeling of material behavior. He had co-authored about 17 papers, and research reports. Of this total, 12 papers have been published after peer review.

\section{Devdas Pai, North Carolina A\&T State University}

Devdas M. Pai is a Professor of Mechanical Engineering at NC A\&T State University and Associate Director of the Center for Advanced Materials and Smart Structures. He teaches manufacturing processes and tribology related courses. A registered Professional Engineer in North Carolina, he serves on the Mechanical PE Exam Committee of the National Council of Examiners for Engineers and Surveyors and is active in several divisions of ASEE and ASME.

\section{Cindy Waters, North Carolina A\&T State University}

B.S. Materials Science, Virginia Tech, M.S. Materials Science, Virginia Tech, PhD. Mechanical Engineering NCA\&T State University. Research interests include advanced materials, thin films and biomaterials. 


\title{
Recitation in Core Engineering Mechanics Courses: Implications for Retention and Student Performance
}

\begin{abstract}
In an ongoing attempt to improve undergraduate education and increasing student retention, the College of Engineering at North Carolina A\&T State University adopted a new system in which recitations become an integral part of core engineering mechanics courses including: Statics, Dynamics, and Mechanics of Materials. Under the new lecture-recitation system, each course contains two one-hour lectures, and one two-hour recitation. The entire class attends the lectures in which the faculty member covers the general topics and provides related sample problems. There are multiple recitation sections operated by the same instructor, consisting of typically 15-20 students, in which students review their lecture notes and solve selected problems. These problems are typically selected from the homework assignments; previous tests and quizzes; and from the Fundamentals of Engineering Exam review materials.

Recitation sections will also help students with non-traditional learning styles to more quickly understand the subject. This in turn will improve retention and result in much-improved course grades and improved FE exam scores for the students, thereby positively affecting the overall academic success of the college.

This paper contains summaries of some of the most recent observations on the role of recitation in increasing student retention and performance. In this investigation the following three core engineering courses are used: Statics for architectural, civil, and mechanical engineering students (CAAE331/MEEN335); Dynamics for architectural, civil, and mechanical engineering students (CAAE 334/MEEN 337), and strength of materials for civil and mechanical engineering students (CAAE332/MEEN336).
\end{abstract}

\section{Introduction}

In college classes, lectures are still the primary mode of content delivery to students. The disadvantages of such methods are: (1) students cannot remember all of the lecture material; (2) students typically record only $20-40 \%$ of the important lecture ideas; (3) approximately $80 \%$ of what is not noted is forgotten after two weeks; (4) lecturing technique is a one-way teaching process (students receive information delivered by faculty). On the other hand, recitation (usually, small class size), allows instructors to become more familiar with their students' strengths, learning styles, and problem areas. It also gives teachers enough time to work more efficiently with students who need extra help. By having smaller classes, teachers are better able to get to know their students, and to develop strategies for helping them succeed by providing more learning options. Research has shown that classes with fewer than 20 students can improve student academic achievement and are particularly beneficial for disadvantaged students (U.S. Department of Education, 1999). Recitation sessions may be considered as diagnostic assessments that help instructors develop early intervention strategies and turn, to stop 
the cycle of failure. By identifying students early on who need extra help, the instructor can provide intensive support and increase the instructional time for struggling students by incorporating supplemental instruction. At our University, supplemental instruction has proven to be very effective, in which it provides one-on-one tutoring with higher level (older) students, and gives struggling students multiple opportunities to learn.

\section{Why Recitation?}

A MathSoft Survey of about 4700 professors and related fields, (Analysis of Higher Education Survey), asked "What do you think is the most common cause for a student dropping an engineering major?" They responded: Difficulty mastering math = 43\%; Poor study habits, social distractions $=34 \%$; Difficulty mastering subject matter other than math $=10 \%$. It is clear that intensive learning, expanded learning options, diagnostic assessments, and intervention strategies are needed, especially for students experiencing difficulties. It should be noted that, to satisfy the above concepts, an increase in instructional time is required. This can be done through the lecture-recitation approach and supplemental instruction.

A significant number of important concepts for understanding retention have been identified by various researchers (Journal of Engineering Education). Most published research in this area focuses on retaining freshmen engineering students, but a few studies cover the upperclassmen level. To investigate the upperclassmen retention (junior and senior engineering students), one may consider: gender; academic ability (scores in prerequisites); academic preparation (hours studies); work plan (hours per week); social integration (friends, participation in group work, and contact with faculty members). In this study, our objective is to focus on the most important issues. Those issues include, but are not limited to, instruction; advising; and student's concern. Such elements are more likely to impact retention and thus must be given high priority. In a survey to understand retention conducted by Kent State University (1996-1997), students indicated that items relating to instruction, course content, and a knowledgeable faculty are the most important issues. One should consider the following factors in depth in relation to recitation sections:

1. A reasonably good teacher should know within the first month of the semester which students will need extra academic assistance. As a result of such knowledge, the teaching and learning strategies and the student's attitude should be adjusted to cope with the academic deficiencies.

2. Teacher expertise has a direct correlation to high student achievement. Therefore, in order to correct academic deficiencies, a faculty member should be an effective teacher who cares about students, is willing to spend time helping them, know the course content, and engage students in the learning process.

3. The instructor should provide meaningful instruction that deal with the significant concepts of a discipline, incorporate critical thinking skills, and allow substantial time for discussion and idea sharing among students (Peterson, 1995).

4. The instructor should create active learning environments to strengthen the relationships among teachers, students, and knowledge. Active environments require 
collaboration and communication, and encourage more analysis than do traditional classrooms (North Central Regional Educational Laboratory, 2000).

5. The instructor should provide more learning options, because not all students learn in the same way, or at the same speed.

\section{How do the Students feel about the recitations?}

We asked students to give us their opinion about the recitation sections and its impact on their performance. These are some of the comments we received:

"As a student in Engineering Mechanics Class - Statics, I wanted to let you know how helpful the recitation portion of the course has been. The relaxed, flexible, problem solving nature of the recitation was an ideal learning environment for me. By "relaxed", I mean no pressure; I felt comfortable (even encouraged) asking questions in the small, open class. By flexible, I mean the focus of the recitation is geared towards the topics the students feel they need additional help with. By problem solving, I mean less theory and more application. Also, the interaction in the classroom helped keep me on my toes (I would not want to show up unprepared for recitation for fear of embarrassment). I have taken several problem solving courses in the engineering curriculum without a recitation. I have found that the courses without recitation equate to much more study time, which is not always available. Recitation saves students time."

"I feel the recitation in this class and all classes I have taken which implemented recitations proved to enhance my understanding and retention of the course material. I have noticed that classes which did use recitations have seemed to escape my memory more so than classes which did implement recitations."

"The recitation is the most important part of the statics class because we clarify our doubts and go over the problems stepwise. Due to the limited time frame of the lectures we usually end the lectures without completely finishing some problems. In the recitation period the instructor has more time to explain the problems in more detail and answer individual questions. I think that the recitation period helps us maximize our learning experience by stressing important concepts. In the recitation we can explore all the applications of every subject we learn. Is the recitation the part of the class in which we can identify our weaknesses and strengths in the subjects taught in class. This helps us be more prepared for the exams. I think all the classes that include math or science subjects should have a recitation period. These classes require more practice in order for the student to develop strong skills and do better in the exams. If we compare classes without recitation with classes with recitation periods remarkable differences can be pointed out. For example, in classes without recitation students tend to do more poorly in the exams and quizzes because they feel less confident due to the lack of practice. In classes with recitation periods the students remember the subjects better due to the constant practice of challenging problems. The recitation definitely helps us "the more we practice the better we get." 
"Recitation in MEEN 337/CAAE 334-Dynamics helped me understand the difficult concepts covered in class. Concepts of velocity, acceleration, and particle vectors are often hard to grasp the first time they are taught. Recitation gave me the extra time needed to understand these concepts and helped me solve homework problems. I find myself often lost, confused, and discouraged when a difficult subject is being taught without a recitation."

"It has been heavily debated amongst the student population whether or not classes that have a recitation benefit versus classes that don't have a recitation. In my personal opinion, having recitation always better than not having one. Recitation allows for the opportunity to implement skills that have been discussed in the lecture with the teacher's assistance that would have otherwise been impossible. True, it is always possible to get extra practice on homework, but it's always better to have input from the teacher, and recitation allows that. Classes that do not have a recitation can be effective, but the extra recitation classes provide more in depth explanation from the instructor, on more specific areas. For example, I have used my prior recitation sessions as a time to review my homework with my professor before I submitted it, or to spend a little extra time working out problems in a subject or area that I had trouble in. There are some classes that don't have a recitation I'm positive that if they did have recitations, I would probably perform much better in those courses. Furthermore, I feel like most if not all classes should offer a recitation, even if it was just optional. Many students out there need extra time to process what they learn. The recitation is a great way to reinforce the course."

"During fall semester of 2006 I was required to take not only statics, but statics recitation as well. Statics recitation has done nothing but help me. Without recitation, there is no way I would have grade I have now. During the recitation you receive one-on-one tutoring the professor helps you understand the material better. The only thing I would change is the time length of the recitation. I believe it needs to be longer or it should be more than just once a week."

"The recitation for this class has greatly impacted my overall performance in statics. The smaller class size allows me to feel more comfortable asking questions. Also, the two hour time period, as opposed to fifty minutes, provides more opportunities for questions regarding the course material to be answered. The recitation has been very effective to me because we are able to apply the material that we learn in the lecture to different problems. This extra practice gives me a better understanding of the topics discussed in the lecture session. The recitation also makes the assigned homework easier to understand because we learn the subject more thoroughly than we do in the lecture."

"The recitation for this class has greatly impacted my overall performance in statics. The smaller class size allows me to feel more comfortable asking questions. Also, the two hour time period, as opposed to fifty minutes, provides 
more opportunities for questions regarding the course material to be answered. The recitation has been very effective to me because we are able to apply the material that we learn in the lecture to different problems. This extra practice gives me a better understanding of the topics discussed in the lecture session. The recitation also makes the assigned homework easier to understand because we learn the subject more thoroughly than we do in the lecture."

"Recitation has definitely had a positive impact on me. This is despite the fact that my grade in class is really low. I could only imagine how much lower it would be if it weren't for a recitation. The instructor is a very knowledgeable and gives good examples. During the recitation, we were encouraged to ask questions. The only thing I can say I would change would be try to limit presenting any new material in recitation. Recitation should only be a study session for previously covered material. I would also consider putting students in a recitation group to put problems on the board for constructive criticism. It would encourage students to learn from one another as well as from the instructor. It promotes teamwork, which is good when the instructor is not available!"

"The field of engineering is all about how to solve problems. While in class, the more problems you work out, the more practice you get and, thus, the faster and better you become. With that said, any additional help is needed and appreciated. I liked having a class for dynamics recitation. I know that in this two-hour time period, I would learn more than if I were to sit in my room for two hours working on the problems on my won. I benefited from all the information and problems that were worked out on the board. The only negative thing is that I wish the recitation was more like the students work on homework problems and the teacher answers our questions rather than a two- hour lecture. Sometimes, I just need to work out the problems myself and I would have liked to have that chance in class rather than waiting until I get back to my room and possible forgetting some information in that time period. Other than that, recitation helped me out a great deal and I'm glad we have them."

"I'm glad that I had the opportunity to learn more from this class by going to the recitation class. Most teachers have very different teaching styles and if a student isn't use to that specific professors teaching style the class will become much harder. But recitation usually clears this problem. I've cleared up more unknown information in recitation than I ever did in class. Class is all about the lecture, and recitation allows students to ask questions rather than cutting class time short by asking them during the lecture. Overall, the recitation was a pretty good idea, but there should be more sections open for the lecture instead of including 75 students in one hot classroom".

In the present study, the results of engineering mechanics courses were used to investigate the effect of the recitation on the student's academic achievement. Figure 1 shows the distribution of the final grades, and the percentage of recitation classes 
attended. Final grades were determined by five categories: homework, three quizzes, three major tests, and a comprehensive final exam. Percentage of attendance was determined by dividing the number of recitations attended by the total number of recitations for the semester. As shown in Figure1, there is a strong direct relation between grades and recitation attendance; students with higher grades have higher attendance record.

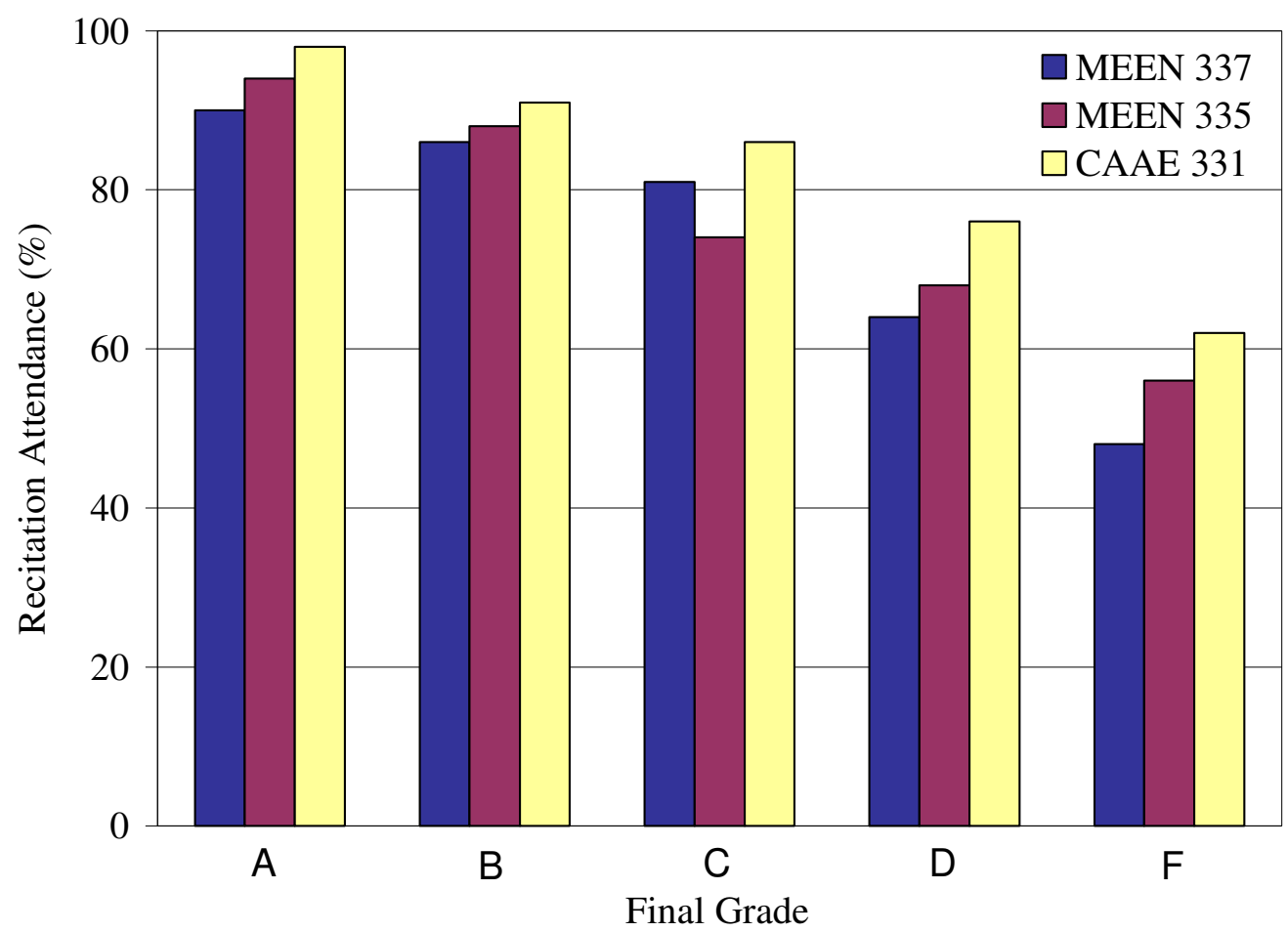

Figure 1. Effect of Recitation Attendance on the Student's Final Grade

\section{The benefits of lecture-recitation approach may be summarized as follows:}

1. Based on the level and type of questions asked during recitations, instructors can measure the academic level of their students. This may lead in selecting the topics that need to be emphasized in the next lectures, (feedback).

2. Recitations improve the skills and ability of students in note-taking, and thus improve their academic success.

3. Help the student rehearse the lecture content, and provide a gauge to what is important in the text. Also, recitation can help the student to remember parts of the material that were covered but not included in the lecture notes.

4. Encourages students to process the material at a deeper level. 
5. Through discussions and solving problems during recitations, students review the current lecture notes before the next lecture. Therefore, lectures will make more sense, new concepts will be less formidable, and students will understand the next lecture better.

6. Doing homework on time and reviewing lecture notes helps orientate the student's thoughts to the subject in hand and makes learning easier.

7. Reading lecture notes, during recitations, will help students to link new ideas to familiar concepts and identify things they didn't quite understand.

\section{References}

1. North Central Regional Educational Laboratory. (2000). Indicator: Engaging learning environments. Available online: http://www.ncrel.org/engauge/framewk/efp/environ/efpenvin.htm

2. Peterson, K. (1995). Creating high-achieving learning environments. Pathways to School Improvement. Available online: http://www.ncrel.org/sdrs/areas/issues/educatrs/leadrshp/le400.htm 